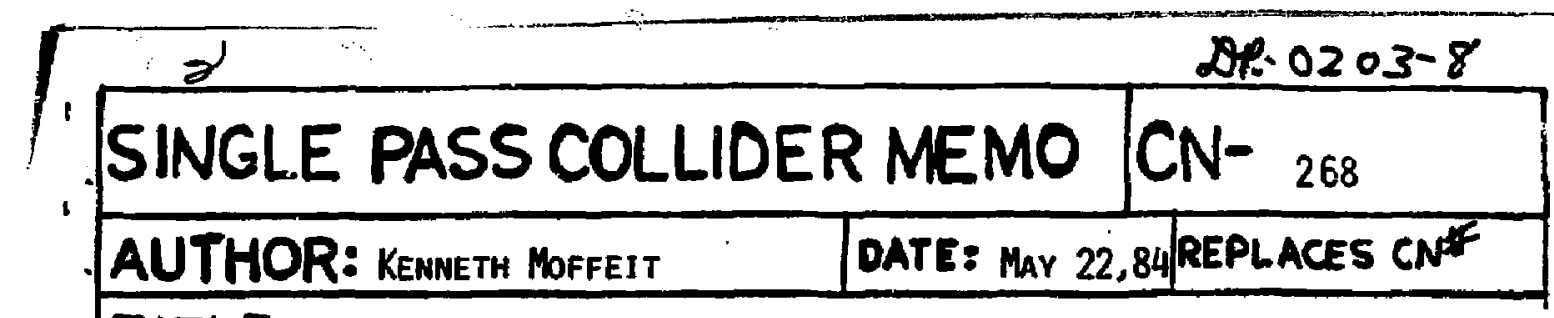

\title{
TITLE: Positron SOURCE: First 50 nanoseconds
}

SLAC-CN- -268

DEB4 012179

Norice

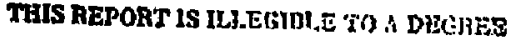

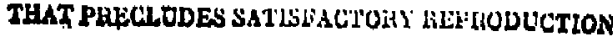

\section{DISCLAMIER}

This report wis prepared as an wecount of woth uponesed by an asency of the United States Government. Neither the United Sute Government nor ay wency thereof, nor any of their employece, makes any warranly, expras or implied, or anumes any legnl linbillity or respoasibility for the accurney, completences, or usefulnese of any information, apparatu, product, of

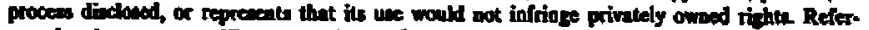

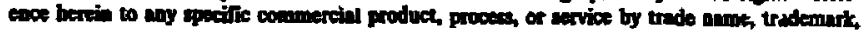
manefacturer, or ofwerwixe does not necesanrily coostitute of imply its endonement, recom-

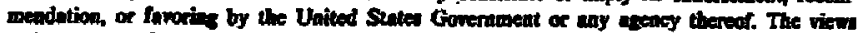

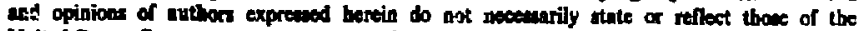
United States Covemment of any agedey thereof.

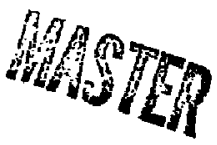

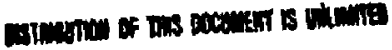




\section{LEGIBILITY NOTICE}

A major purpose of the Technical Information Center is to provide the broadest possible dissemination of information contained in DOE's Research and Development Reports to business, industry, the academic community, and federal, state, and local governments. Non-DOE originated information is also disseminated by the Technical Information Center to support ongoing DOE programs.

- Although large portions of this report are not reproducible, it is being made available only in paper copy form to facilitate the availability of those parts of the document which are legible. Copies may be obtained from the National Techinical Information Service. Authorized recipients may obtain a copy directly from the Department of Energy's Technical Information Center. 